\title{
IMAGINARIO SOCIAL DEL CUERPO DE LA MUJER EN LA PRENSA POPULAR DE CHILE. UNA PROPUESTA PARA SU ANÁLISIS
}

\author{
SOCIAL IMAGINARY OF THE BODY OF WOMAN IN CHILEAN POPULAR \\ PRESS. A PROPOSAL FOR ITS ANALYSIS
}

Norma Huerta A.

Rodrigo Browne S.

Amalia Ortiz de Zárate F.

Marcela Hurtado R.

\section{Resumen:}

El objetivo de este texto es analizar el imaginario social del cuerpo de la mujer en el diario de corte popular "La Cuarta" de Chile, desde la perspectiva de la transformación del cuerpo por la modernidad, que implanta una concepción reificante de éste y que es reproducida por los medios de comunicación. Como estrategia metodológica se propone la utilización del Análisis Crítico del Discurso Periodístico.

\section{Palabras claves:}

Imaginario social, cuerpo, imagen técnica, medios de comunicación.

\section{Abstract:}

The objective of this work is to analyze the social imaginary of the woman body in the Chilean popular newspaper "La Cuarta", from the perspective of the transformation of the body by the modernity, that establishing a reificant conception and that is reproduced for the mass media. As methodological strategy of the cualitative character, we propose the use of the matrix named Journalistic Critical Discourse Analysis.

\section{KEY WORD:}

Social imaginary, body, technical image, mass media 


\section{Introducción}

$\mathrm{Al}$ encender la televisión, al escuchar un programa de radio, al leer la prensa, o al navegar en internet, llaman la atención los contenidos publicitarios que están dirigidos hacia las mujeres. ¿Qué promocionan? Liquidaciones y ofertas de productos que han de embellecer su figura, recetas mágicas que hacen desaparecer las arrugas, las manchas, el cabello blanco, la vejez; tratamientos para adelgazar, indumentarias para estar a la moda, toda una serie de productos creados por la ciencia y su técnica con el propósito de alterar los ciclos biológicos de un cuerpo que, al parecer, avergüenza. De hecho, los cuerpos femeninos que, precisamente, promocionan estas mercancías se corresponden a cuerpos perfectos así como los ha modelado y nos impone la modernidad (Le Breton, $1995)^{1}$.

El filósofo Günther Anders (2007) denomina a este apocamiento "vergüenza prometeica", es decir, vergüenza frente a la perfección de las producciones hechas por el ser humano, quien toma conciencia de su origen fruto de una evolución casual, no manipulada, compleja e imperfecta, y la niega. Siente vergüenza de haber "devenido en vez de haber sido fabricado" (Anders, 2007: 37) en base a procesos calculados. Este sentimiento, por tanto, surge de la relación entre una persona y un objeto ¿qué sugiere esta última afirmación si la vergüenza mana cuando me comparo con otro cuerpo? El hombre y la mujer quieren convertirse en un self-made man (Anders, 2007: 37), una mercancía.

Ahora bien, en 1957 el francés Roland Barthes agrupó en un texto llamado Mitologías una serie de ensayos analíticos en torno a ciertos acontecimientos de la vida cotidiana, como por ejemplo, la publicidad, el cine, los espectáculos, etc., con el objetivo de demostrar que algunos signos de la cultura contienen en sí mismo connotaciones que dan cuenta de los imaginarios sociales o mitos manifiestos (Durand, 2000) de una sociedad.

Así también podemos abordar a la prensa escrita interés de la propuesta que se presenta en este texto, disfrazada por el principio de la objetividad del que hace alarde el periodismo y que aún se enseña en las universidades. Sus noticias, pueden ser abordadas como "mitemas", vale decir, como unidades semánticas básicas de un

1 Sin duda también nos encontramos con muchos más productos que, así como los descritos, buscan instalar o consolidar un imaginario social de la mujer, como el caso de los artículos para aseo, detergenteAs, suavizantes, desinfectantes; los vinculados a la infancia, pañales, comida, juguetes; a la cocina, bases para preparar salsas, sopas, mayonesas con bajas calorías, alimentos "light", etc., donde se ratifica la relegación de la mujer al espacio de lo privado, la casa, el hogar, y, por supuesto, a la maternidad. Aún cuando se introduzca la visión de la mujer que trabaja fuera de su casa estos productos continúan dirigiéndose a ésta, asumiendo (o más bien, imponiendo) el hecho de que las mujeres sigan desempeñando las labores de limpiar, cocinar y criar. Lo interesante es que la imagen o imaginario que se utiliza de esta mujer es, justamente, aquella del cuerpo perfecto, por ejemplo, se muestran madres y dueñas de casa acicaladas, delgadas y jóvenes. discurso, por medio de las cuales se pueden conocer las matrices arquetípicas de un conjunto imaginario predominante de una época y sociedad determinadas (Durand, 2000).

Entonces, cabe preguntarse por las características que podemos encontrar en las noticias del segundo medio escrito más leído en Chile, el diario La Cuarta², respecto al cuerpo de la mujer, en tanto fragmento, trozo, que contiene en sí mismo "al todo" (principio hologramático) (Morin, 1994: 107 y Durand, 2000: 106), es decir, al mito dominante naturalizado, tal vez ya no el de la burguesía como lo entendía Barthes (2005) que diera origen a los Estados-naciones (Fernández Serrato, 2005) sino al de las grandes e invisibles transnacionales de la técnica o del Imperio (Hardt y Negri, 2002).

\section{Cuerpo y téCNICA. LA ReIFICACIÓN DEL CUERPo}

El sociólogo francés David Le Breton (1995) advierte queel discurso dela modernidad ha provocado una ruptura y borramiento del cuerpo. Se trata del discurso de Occidente, mezcla de pensamiento socrático y cristianismo, que ha impuesto a sí mismo y al resto, una verdad monoteísta, unidireccional, única (Durand, 2000). Regido por el "paradigma de simplificación"3 (Morin, 1994) cuyos principios son la "disyunción, reducción y abstracción", que impone un pensamiento binario que condicionará el conocimiento del mundo a partir del siglo XVII.

Bajo esta lógica dualista, se sustenta la tesis del borramiento del cuerpo consistente en que aún cuando el cuerpo -en tanto medio primario de comunicación (Baitello, 2008)- está presente objetivamente, su represión producto de prácticas sociales institucionalizadas (normatividad de los espacios, control del deseo sexual, cuerpos higienizados, jóvenes, etc.), logran negarlo, borrarlo hasta volverlo transparente. Su efecto es la fragmentación cuerpo-sujeto (Le Breton, 1995). Así se puede ver representado en la película de Charles Chaplin, “Tiempos Modernos" (Estados Unidos, 1936), crítica a la representación del cuerpo como un engranaje más de la gran maquinaria del progreso moderno, por lo tanto, cuerpo constituido en artefacto.

Vinculado a lo anterior y, como ya mencionamos, el hombre y la mujer quieren convertirse en un self-made man, en un producto, en una mercancía (Anders, 2007). Así la "vergüenza prometeica" se constituye en un síntoma de lo que se denomina "reificación o cosificación", concepto desarrollado por el filósofo húngaro, Gyorg Lukács que plantea que el ser humano, sometido a las leyes del mercado, comienza a

2 "La Cuarta" es el segundo diario más leído en Chile, después de "El Mercurio", de acuerdo al Boletín de Circulación y Lectoría $2^{\circ}$ Semestre de 2013 de Valida (Validación de circulación y lectoría) referencia: http://www.achap.cl/estudios.php Cabe señalar que "La Cuarta" pertenece al grupo periodístico "Copesa"

3 Edgar Morin desarrolla esta concepción a partir de la revisión del trabajo del filósofo, físico y matemático René Descartes (1596 - 1650).

Revista Internacional de Culturas y Literaturas, abril 2015 
percibirse ya no como un sujeto, sino como un objeto (Anders, 2007). El síntoma de la "vergüenza prometeica" está asociado a una segunda etapa de esta reificación, a saber, "la etapa en que el ser humano reconoce la superioridad de las cosas, se coordina con ellas, afirma su propia reificación o rechaza su propia no-reificación por deficiente" (Anders, 2007: 43). Pero, además, Anders sugiere que la humanidad ha alcanzado una tercera etapa en la historia de la cosificación consistente en que la aceptación o el rechazo de su propia reificación se ha vuelto algo tan natural, que "ya no lo experimenta como un juicio, sino como un sentimiento" (Anders, 2007: 42 y 43).

Este autor propone un ejemplo de esta tercera etapa, en torno al make-up, al maquillaje de las chicas. Aquí desarrolla la idea de que éstas sienten vergüenza de mostrarse ante otras personas sino están maquilladas. El punto es qué entienden por estar maquilladas, la respuesta sugerida por Anders es,

Cuando se han trasformado (en la medida en que la materia prima de sus miembros y sus rostros lo permite) en cosas, en objetos de arte industrial, en productos acabados. Es <<imposible〉> aparecer en público con las <<uñas sin pintar >>: sus uñas solo están listas para el salón, para el trabajo, incluso para la cocina, cuando son elevadas a $<<$ igual rango $>$ que los aparatos que sus dedos deben manipular; cuando presentan el mismo <<acabado〉> frío y pulido de cosa que caracteriza a los aparatos; cuando pueden renegar de su pasado orgánico; es decir, cuando dan la impresión de que también ellas han sido fabricadas. La misma regla es aplicable al cabello, a las piernas, a la expresión del rostro, de hecho, al cuerpo entero [...]. (Anders, 2007: 43 y 44)

Es interesante apreciar que el filósofo plantea que, en este contexto, el sentido del concepto de "cuerpo desnudo" muta, pues ya no se trata de un "cuerpo desvestido" sino más bien de un cuerpo que no ha sido intervenido por la técnica, o sea, un cuerpo que no consta de elementos vinculados al proceso de la reificación (Anders, 2007). Por ello la relación comparativa que acarrea la "vergüenza prometeica" entre una cosa y un ser humano, entre un cuerpo y otro cuerpo.

Por consiguiente, se busca vestirnos con otros cuerpos. El teórico de la comunicación Norval Baitello Jr. (2008) identifica (no sin asumir que existen una multiplicidad de otras posibilidades) a tres tipos de estas vestiduras de cuerpos: El "cuerpo bomba", el "cuerpo química" y el "cuerpo máquina".

El "cuerpo bomba" deriva de la convicción de que los seres humanos han sido creados a imagen y semejanza de los dioses, es decir, su origen es de carácter divino $\mathrm{y}$, por lo tanto, su cuerpo es el reflejo de las deidades. No obstante, el cuerpo en tanto materia, plantea lo contrario. Así, fue sometido a "un largo y duro proceso de domesticación y civilización, cabía superarlo en su condición material y visible, cabía devolverlo inefable e invisible, inmaterial como los dioses. O también, cabía destruirlo, transformándolo en imagen, construyendo un cuerpo efigie". Estas divinidades también se corresponden con las del mercado: el trabajo, el dinero, la moda, etc. Por lo que no sólo aquellos terroristas que en nombre de un Dios han inmolado su propia existencia caben en esta "posibilidad" (Baitello, 2008: 67).

El "cuerpo química", corresponde a aquellos que son productos de procesos biológicos, bioquímicos controlados por la manipulación genética en situaciones experimentales de laboratorio: "Todo presente es sólo el escenario de proyectos futuros, el pasaje para la inexorable evolución, para el proceso de los cambios metabólicos perfectos" (Baitello, 2008: 69).

Y finalmente, el "cuerpo máquina", concepción que se busca rescatar aquí vinculada, justamente, al proceso de reificación antes descrito. Se trata de un cuerpo confeccionado por el ser humano, ya no de un cuerpo creado por los dioses o por la evolución biológica. Sus inicios se remontan al desarrollo y uso de herramientas y su consecución se reconoce en la incorporación de esas herramientas en su propio cuerpo $\mathrm{o}$, en la modelación y generación de éste a imagen y semejanza de las herramientas: "los experimentos y transformaciones quirúrgicas, las diferentes prótesis sustitutivas o transformadoras ejemplifican la fabricación del propio cuerpo" (Baitello, 2008: 69).

El cuerpo-máquina responde a una funcionalidad específica para la productividad y eficiencia y no consta de pasado ni de futuro. En tanto artefacto, está destinado a la obsolescencia y a ser desechado. Por eso su insistencia sólo en el presente. En tanto cosa, objeto, su capacidad de reflexión es nula. Baitello (2008: 69) señala: “El cuerpo máquina es todavía objeto de encantamiento y adoración por su perfección apolínea, por su obediencia total y absoluta a los cánones de las formas y de las funciones correctas, por su pertenencia a la norma-patrón, lo que equivale a decir, por su uniformidad como todos los cuerpo máquina".

3. ImAGINARIOS SOCIALES DE LA MODERNIDAD: EL CUERPO "DEVORADO" POR LA IMAGEN TÉCNICA

Gilbert Durand en su libro Lo imaginario (2000) desarrolla una revisión crítica de los cambios culturales que han estimulado las nuevas formas técnicas de producción reproducción y transmisión de imágenes, creadas con una intención mercantil de consumo. Plantea la banalidad de pensar que el siglo XX ha visto reedificar una civilización de la imagen, proceso cuya consecuencia es una revuelta total en las filosofías que planteaban la preponderancia de la imprenta y de la comunicación escrita por sobre la imagen mental, que reducían a ésta última a una mínima expresión. El autor va más allá, planteando que estas nuevas formas técnicas, han provocado una ruptura, una verdadera revolución cultural, una huida de los espacios dominados por la "filosofía de biblioteca y de escritura", herencia del mundo occidental, se trata de la "explosión vídeo", "efecto perverso" de la modernidad, en tanto no fue previsto y desmiente 
sus bases teóricas (Durand, 2000: 17, 18, 46 y 48). He aquí la gran contradicción que identifica el antropólogo francés: la "revolución vídeo" es una de las consecuencias de la "iconoclasia tecno-científica" de occidente, vale decir, occidente históricamente ha dado muestras de una negación, de una destrucción de las imágenes, empero, ha producido una deificación de éstas. Su creación, precisamente, se debe al desarrollo de los avances científicos y técnicos de la modernidad.

Pero ¿qué sucede cuando nuestra capacidad de simbolizar se ve afectada, medrada y casi destruida por un caudal incesante y veloz de imágenes técnicas? ¿Cómo se constituye este imaginario social, en tanto enjambres de representación del mundo?:

La enorme producción obsesiva de las imágenes se ve contingenciada en el dominio del $<<$ distraer $>>$. Y no obstante, los difusores de las imágenes -digamos los $<<$ medios de comunicación de masas >>- están omnipresentes en todos los niveles de la representación, de la psique del hombre occidental u occidentalizado. Desde la cuna hasta la tumba, la imagen está aquí, dictando las intenciones de productores anónimos u ocultos: desde el despertar pedagógico del niño, desde las elecciones económicas, profesionales del adolescente, desde las elecciones tipológicas (el look) de cada uno, en las costumbres públicas o privadas, la imagen mediática está presente, unas veces presentándose como <<información〉》, otras veces escondiendo la ideología de una $<<$ propaganda $>>$, y otras convirtiéndose en $<<$ publicidad $>>$ seductora ....La importancia de la $<<$ manipulación icónica > (relativa a la imagen) todavía no es inquietante; no obstante, de ella dependen todas las demás valorizaciones, incluyendo la de las <<manipulaciones genéticas >>. (Durand, 2000: 49)

El objetivo ahora no es negar la imagen, sino controlarla, hacerla fluir ilimitadamente y utilizarla para que ellas devoren a la imaginación (Baitello, 2008) para modelar las visiones de mundo, para controlar los imaginarios en beneficio del mercado, Dios todopoderoso de la tierra, que busca que los seres humanos simbolicen sus interacciones a través de las leyes de la economía. Para que ellos también se conviertan como revisamos, en una mercancía.

Una de las principales herramientas técnicas para llevar a cabo este propósito son los medios de comunicación, como bien advierte Durand (2000). Su utilización hará que la histórica forma de relación entre el ser humano y el mundo se transforme hasta casi desaparecer. Puesto que no se trata solo de "medios", que pueden ser utilizados de acuerdo a ciertos fines precisados por los usuarios, lo que implicaría un acto de libertad, sino más bien, se trata de fines en sí mismos, de "hechos que nos marcan" (Anders, 2007: 46)

Günther Anders pone un ejemplo en relación a esta afirmación. Pues, efectivamente, se puede utilizar la televisión con la intención de participar en una misa, pero lo que verdaderamente "marca" o "transforma" al espectador no es el hecho de que esté ausente del acto material de la liturgia, sino más bien, de que solamente esté consumiendo su imagen (Anders, 2007: 47).

Y como la misa, se transmiten los partidos de fútbol y se deja de ir al estadio, se transmiten los conciertos, se transmiten los viajes, las fiestas religiosas, etc. Los seres humanos dejan de ir al mundo para conocerlo, para experimentarlo, para vivenciarlo, puesto que el mundo se le entrega embasado en su domicilio, en su habitación (Anders, 2007). ¿Pero lo que se nos entrega es realmente el mundo o es una re-presentación, una simbolización estructurada y estructurante de lo que otros quieren que se experimente como tal?: “La relación entre el ser humano y el mundo se vuelve unilateral. El mundo, ni presente ni ausente, se vuelve fantasma" (Anders, 2007: 53)

En la televisión, en la radio, o internet los hechos parecen estar realmente presentes. Pero ¿acaso la presencia no implica la intervención en tanto relación dialógica?, es decir, los acontecimientos transmitidos por estos medios intervienen en la intimidad hogareña de los seres humanos, los interpelan, los modifican, los marcan...y el ser humano ¿puede hacer lo mismo con ellos? ¿Puede preguntarles, responderles, dar su opinión acerca de lo que están mostrando? Los medios de comunicación condenan a los seres humanos al "mutismo" y con ello "le arrebatan todo poder", les quitan la libertad y "el que no es libre, ¿no está más bien ausente, porque se le trata como si no existiera, como un no-ser, y no puede tener nada que comunicar con él mismo? Consecuentemente, los acontecimientos que se muestran por estos medios, están presentes, pero al mismo tiempo, ausentes, son reales y aparentes, en resumen, señala Anders, son así, porque se trata de "fantasmas", de "algo intermedio entre el ser y la apariencia" (Anders, 2007: 54, 55 y 58) se pierde el presente y la presencia del mundo (Baitello, 2008).

Y estos fantasmas mantienen "sedados" a los seres humanos, es decir, los mantienen sentados con el propósito de tranquilizarlos, de calmarlos, de tenerlos tranquilos, de domesticar su pensamiento y su cuerpo, medrando su capacidad de ir hasta el mundo, de simbolizarlo, de descifrarlo y de transformarlo (Baitello, 2008: 43). Su principal estrategia es la retransmisión de imágenes creadas por la técnica que fluyen infinitas y raudas inutilizando la posibilidad de que sean decodificadas.

La imagen como escritura, sin duda posibilitaba el espacio y el tiempo para ser interpretada cabalmente, para descifrar, para confrontar, para dialogar con las imágenes interiores, dirá Baitello (2008), que generaban. Así, los seres humanos se alimentaban de las imágenes, enriquecían su pensamiento, su mundo interior a través de su desciframiento. Pero en la actualidad, la rapidez, la anulación del tiempo en los medios de comunicación, invierten este proceso. La incapacidad de decodificar el flujo incesante o más bien, el bombardeo continuo de imágenes, está cambiando 
esta relación, la está invirtiendo: “En el momento en que no las desciframos, no nos apropiamos de ellas y ellas nos devoran" (Baitello, 2008: 41).

\section{Imaginario social del cuerpo de la mujer en la prensa. un propuesta para su análisis}

La propuesta de análisis que se presenta aquí se basa en la aplicación de una matriz metodológica diseñada y propuesta para un Análisis Crítico del Discurso (ACD) Periodístico (Browne, 20074) que se distribuye en dos planos:

\section{1.- Plano Significado/texto}

1.1.- Nivel temático: significados globales: Se trata los temas a que se refiere el texto, en donde se busca identificar de qué habla, qué macroestructuras semánticas es posible deducir del discurso, cómo se unen éstas macroestructuras y cuáles son los presupuestos que se manejan acerca del discurso sobre "el otro", en este caso, del cuerpo de la mujer, que interesa investigar.

1.2.- Nivel de significados locales: Consiste en el significar literal de las palabras, en donde podemos encontrar, por ejemplo, descalificaciones. Este nivel a su vez se divide en:

a) De carácter implícito o indirecto: Son informaciones que se pueden inferir de palabras del texto (el texto no lo expresa explícitamente) como implicaciones, presupuestos, alusiones, ambigüedades, hipérboles, etc.

b) De carácter explícito o directo: Son informaciones evidentes en las palabras del texto. Estrategias léxicas (estilo) utilizadas por los periodistas que conllevan implicaciones ideológicas que pueden dar a entender la opinión del redactor y del medio en general sobre el suceso.

\section{2.-Plano Formal/texto- contexto}

2.1.- Estructuras formales sutiles: En este plano se intentará evidenciar los modelos mentales presentes en el texto, aquellos formatos globales y locales que se pueden caracterizar por incidir menos en el control consciente de las noticias por parte de los receptores. Se busca observar cómo operan los aparatos ideológicos formales del discurso que pueden emitir falacias, omitir información crucial dando cuenta de los discursos de dominación en tanto imaginarios sociales.

2.2.- Nivel Contextual: Consiste en el contexto, es decir, en las representaciones mentales de la memoria a largo plazo, en donde se almacena la experiencia sobre lo vivido. En síntesis, lo que se recordará, posteriormente, es el modelo mental que se

4 Este autor desarrolla esta matriz a partir de los trabajos desarrollados por Teun van Dijk en torno al ACD. construye a partir de lo emitido contextualmente en la noticia que da cuenta de un imaginario social dominante.

A continuación se mostrará la aplicación metodológica.

\section{Noticia}

\section{MATRIZ DE ANÁLISIS}

\section{TITULAR:}

Epígrafe: "Quedó con 300 cc en cada pechuguita y las lucir en Primer Plano".

Título: "Ahora es Fanny 'Pardete' Cuevas".

Bajada: "No debe ser fácil llegar y entregarse a las manos d un galeno de hule para que te entre a picar la humanidad. ¡Es que no somos un roboc!"

Pie de foto:

"Así fue la operación. Casi tres horas duró la operación de m tía. Y ojo, que además se limó el huesito de la nariz. Mañana la veremos en Primer Plano".

"Esta noche conoceremos las nuevas callababys de morenaza, ya que las mostrará en el estelar farandulero de Chilevisión".

\begin{tabular}{|} 
Periodic: La Cuarta \\
\hline Periodista: Rolo Ricciulli \\
\hline $\begin{array}{l}\text { Fecha: Viernes 20 de } \\
\text { julio de 2012 }\end{array}$ & Página: E 41 \\
\hline 1.-Pano Significado/texto \\
\hline 1.1.- Nivel tematico: significados globales:
\end{tabular}

1.1.- Nivel tematico: significados globales:

El texto plantea que un personaje televisivo del espectácul chileno, Fanny Cuevas (programa juvenil de la tarde "Yingo"), se sometió a una cirugía para aumentar el volumen de sus mamas y, para corregir su nariz. Anuncia que el estreno de este cambio lo realizará en un programa de farándula de la TV 


\section{2.- Nivel de significados locales:}

\section{a) De carácter implícito o indirecto:}

“Ahora es Fanny 'pardete' Cuevas".

Sugiere que esta cirugía es tan relevante que hará que Fanny cambie de nombre, es decir, su apellido ahora estará determinado por sus implantes de silicona. "Pardete" se refiere a "Par de tetas". Si se suma la consideración d que en el epígrafe se muestra la cifra del peso de los implantes, la intención es impactar con el volumen, con lo "grande" que serán estos implantes.

“ $Y$ ojo, que no son como una bolsita de té, sino ella quería 375 cc por lado".

Supone que se trata de implantes de silicona muy abundantes al hacer la omparación con "una bolsita de té" que representa lo diminuto.

“Pero mi socia, habilosa ella, no halló nada mejor que mostrar su ambio de airbags para las cámaras de los siempre listos de Primer Plano, donde esta noche lucirá su soñada y mejorada delantera con neblineros".

Al utilizar la palabra "habilosa", refieren a que Fanny es hábil y diestra especto a la toma de decisión de mostrar su cirugía en un program farandulero. Hace referencia, suspicazmente, a un manejo mediático de ese acontecimiento: la venta de exclusividad.

"Ahora dicen que la chicoca quedó como musa inspiradora. De frente de espalda".

Esta afirmación que corresponde al cierre de la noticia resume la opinión a perspectiva que en general asume el texto. Justamente refiriendo que anny luego de la operación ha adquirido un cuerpo que la asemeja a un musa, es decir, deidad reinada por Apolo y que habitaba en el Parnaso.

\section{b) De carácter explícito o directo:}

“Por eso es que mi tía andaba terrible saltona”; "Estoy muy ansiosa" Fanny entró en pánico"; "Se asustó un poco y los nervios casi le juegan una mala pasada".

2.- Plano Formal/texto-contexto

\section{1.-Estructuras formales sutiles:}

En la noticia se alude a imaginarios del cuerpo femenino fuertemente marcados por el sueño del estrellato televisivo. La juventud y la perfección son los ejes modelizantes.

Se desarrolla como una de las ideas centrales la realización de una cirugía de implante de siliconas para aumentar el volumen de las mamas de Fanny como un anhelo de vida, consolidándose la modificación quirúrgica como un medio real y cercano para obtener la felicidad. Por esta razón además, se normaliza la cirugía aplicada en la nariz.

El cuerpo se muestra en tanto mercancía que es "tasable" y "transable" en el mundo de la TV por dinero, es decir, Fanny "vende" la exposición de su cuerpo a un programa de farándula. Eso la hace ser "habilosa", diestra, inteligente, pero frívola manipuladora. Empero, al sumarle calificativos "positivos" que connotan belleza y perfección, la frivolidad se legitima como cualidad.

La constante comparación de las mamas con cosas, las termina también transformando en objetos. Así mismo, se plantea la idea de "arreglar" de "limar" la nariz que en estado natural parec estar desarreglada, maltrecha, malhecha, accidentada.

Se plantea la idea de reflexión en torno a la complejidad de una cirugía y consideración de que no es una máquina. Sin embargo, al utilizar un lenguaje popular, tiende a jugar con esta afirmación y surte el efecto contrario.

Finamente, el que le otorguen la característica de "mus inspiradora" a Fanny, conlleva a asumir la perfección, la validación, la legitimación, lo correcto de sus actos, ya que la diviniza, la asemeja a los dioses.

Fanny representa el sueño consolidado de tener un cuerpomáquina de las adolescentes chilenas. 


\section{2.- Nivel Contextual:}

La legitimación de este acontecimiento esta dado por un contexto cultural en que la modernidad nos impone la imagen de un cuerpo joven y perfecto. De acuerdo a la Sociedad Internacional de Cirugía Plástica Estética (ISAPS) (http://www saps.org/) precisamente las cirugías más efectuadas se vinculan l lifting de rostro, y al borramiento de arrugas en párpados en la frente, signos evidentes de vejez. Así mismo indica que el público que más recurre a éstas tiene entre 21 y 50 años, on mayoritariamente mujeres que corresponden a un $88 \%$. Mientras que los hombres corresponden a un $12 \%$.

Se trata de un mercado que va en aumento con tratamiento ntegrales de modificación corporal que van disminuyendo su costos para dar mayor asequibilidad a las personas.

Un factor determinante en este contexto son las imágenes ransmitidas por los medios de comunicación, sobre todo, aquellas presentadas por los programas de farándula que parecen tomarse las pantallas chilenas. En estos programas e realizar este tipo de intervenciones pasó a ser ya no una novedad sino una constante

\section{Conclusiones.}

El sueño de un cuerpo perfecto, un cuerpo-máquina (Baitello, 2008), reificado (Anders, 2007), creado por la técnica, parece haberse constituido en los sueños de una sociedad.

Anulada la capacidad de descifrarlas, las imágenes que imponen imaginarios de cuerpos de mujer con implantes de siliconas, raquíticos, voluptuosos, colmados de sexualidad, terminan por devorarnos (Baitello, 2008). Las posibilidades de la fantasía se limitan, los sueños se homogenizan. El cuerpo de la mujer pasa a ser un objeto, una mercancía más en el mercado de la medicina, de los medios de comunicación de la publicidad, del sexo. Sin embargo, no se renuncia a concebirla como un cuerpo histerizado (Foucault, 2005). Sigue siendo madre y esposa, además, proveedora, sus funciones aumentan, en tanto cuerpo-máquina, debe responder, producir y no envejecer, mantenerse siempre bella. Para ello se han normalizado y democratizado los procesos técnicos intervencionistas de su propia naturaleza. Sus relaciones simbólicas están dadas por las leyes del mercado.
Así, lo imaginario se constituye, dirá Kamper en "el nombre colectivo para los fallecidos sueños de la humanidad; para los artefactos degenerados de la potencia imaginativa (1994: 1)". La conciencia moral de occidente no se altera, su argumento es la histórica desvalorización de la imagen que ha aclamado negando a uno de sus principales engendros: la revolución vídeo (Durand, 2000). Y, por consiguiente, no logra ver sus consecuencias.

Por último, vemos al Prometeo audaz que le robó el fuego a los dioses del Olimpo para entregárselo a los hombres avergonzado preguntándose, como señala Anders, "<<iQuién soy yo ya?»> [....] bufón de su propio parque de máquinas, $<<i$ Quién soy yo ya?>" (2007: 37).

\section{REFERENCIAS BIBLIOGRÁFICAS}

Barthes, Roland, Mitologías, Buenos Aires, Siglo XXI Editores Argentina, 2005.

Baitello, Jr. Norval, La Era de la Iconofagia. Ensayos sobre comunicación y cultura. Sevilla, ArCibel editores, 2008.

Browne, R. (2007): “Comunicación intercultural y periodismo intercultural: análisis crítico de la construcción social de la realidad a través de la representación mapuche y peruanoboliviana en las noticias de la prensa diaria de cobertura nacional (Copesa y El Mercurio)". Proyecto de iniciación en Investigación, Comisión Nacional de Investigación Científica y Tecnológica (CONICYT) (Grupo de Estudio Sociología CS I). Ministerio de Educación. Chile.

Durand, G., Lo Imaginario, Barcelona, Ediciones del Bronce, 2000.

Anders, G., Antología Günther Anders. Filosofía de la Situación. En de Vicente Hernando, C., (edit.), Madrid, Los libros de la Catarata, 2007.

Fernández Serrato, Juan C., "Archicultura Pop y Comunicación Intercultural", I/C Revista Científica de Información y Comunicación, 2 (2005), pp. 79-104.

Foucault, M., Historia de la sexualidad 1. La voluntad de saber. Buenos Aires, Siglo XXI, 2005.

Hardt, M. y Negri, A., Imperio, Buenos Aires, Paidós, 2002.

Kamper, D., Bildstörungen Im Orbit des Imaginären, Stuttgart, Cant Verlag. Traducción inédita del Dr. Breno Onetto, 1994.

Le Breton, D., Antropología del cuerpo y modernidad, Buenos Aires, Ediciones Nueva Visión, 1995. Morin, Edgar, Introducción al pensamiento complejo, Barcelona, Gedisa, 1994. 